\title{
DAS CELAS AOS CÍRCULOS: POSSÍVEIS CONTRIBUIÇÕES DA JUSTIÇA RESTAURATIVA PARA UM NOVO PENSAR DA JUSTIÇA CRIMINAL
}

\author{
${ }^{1}$ Camila Diógenes de Mendonça \\ 2 Juliana Trindade Ribeiro Pessoa Pordeus
}

Resumo:

Este trabalho procura tensionar o retributivismo do sistema de justiça criminal com a justiça restaurativa. Para tanto, partiu-se da perspectiva abolicionista, que relaciona o cárcere, o capitalismo e a marginalização social. Ante esse cenário, tentou-se entender em que medida a perspectiva do diálogo-consenso é capaz de romper com a lógica do crime e castigo. Nesse contexto, descreveu-se um protótipo de justiça restaurativa em Novo Hamburgo, para os casos que tratam da violência doméstica e familiar contra a mulher. Ao final, tentou-se entender em que medida a justiça restaurativa pode ser encarada como uma prática emancipadora no contexto brasileiro.

Palavras-chave: Sistema Penal; Crime e Castigo; Abolicionismo; Justiça Restaurativa; Violência Doméstica.

\section{FROM PRISONS TO CIRCLES: POSSIBLES CONTRIBUTIONS OF RESTORATIVE JUSTICE TO A NEW STANDPOINT IN CRIMINAL JUSTICE}

\begin{abstract}
:
This work intends to tension the retributivism of the criminal justice system with restorative justice. Therefore, it started from the abolitionist perspective, which relates prison, capitalism and social marginalization. Vis-à-vis, it was attempted to comprehend to what extent the perspective of dialogue-consensus is capable of breaking with the logic of crime and punishment. In this context, a prototype of restorative justice was described in Novo Hamburgo, for cases dealing with domestic and family violence against women. In the end, we tried to understand to what extent restorative justice can be seen as an emancipatory practice in the Brazilian context.
\end{abstract}

Keywords: Penal System; Crime and Punishment; Abolitionism; Restorative Justice; Domestic Violence; Emancipation

\section{INTRODUÇÃO}

\footnotetext{
1 Mestranda pelo Programa de Pós-Graduação em Direito da Universidade Federal de Pernambuco. Graduada em Direito pela Universidade Federal do Rio Grande do Norte. Coordenadora do Núcleo de Direito Criminal da Universidade Federal do Rio Grande do Norte. Estagiária de Pós-Graduação do Tribunal de Justiça do Estado do Rio Grande do Norte. E-mail: camila.diogenesm@ufpe.br

2 Mestranda pelo Programa de Pós- Graduação em Direito da Universidade Federal de Pernambuco. Especialista em Ciências Criminais pela Pontifícia Universidade Católica de Minas Gerais. Graduada em Direito pelo Centro Universitário de João Pessoa. Integrante do Grupo de Pesquisa Política Criminal, Sistema Penitenciário e Direitos Humanos (GPOC/UFPB) junto ao CNPq. Integrante do Grupo de Pesquisa Sistema Penal, Democracia e Direitos Humanos junto ao CNPq. Advogada. Membro da Comissão de Combate à Violência e Impunidade contra à Mulher da OAB - PB. E-mail: julianatrppordeus@gmail.com.
} 
O Código Penal brasileiro, recheado de tipificações criminalizantes, descreve condutas específicas e impõe respectivas sanções, chamadas de penas em abstrato. Tomando como exemplo o art. 157 deste diploma, é disciplinado que subtrair coisa alheia móvel, para si ou para outrem, mediante grave ameaça ou violência, configura o crime de roubo, sujeito a reclusão de quatro a dez anos. Via de regra, então, qualquer indivíduo, atingida a maioridade, que efetue a conduta descrita no caput, deverá ser acusado pelo Ministério Público, defendido por um advogado - público ou particular - e julgado pelo Estado-juiz.

Pela descrição acima realizada, alguns aspectos saltam aos olhos. O primeiro deles diz respeito à dimensão sancionadora dos delitos penais. Afinal, os crimes previstos no Código Penal estão sempre acompanhados da respectiva punição, o que solidifica uma lógica bastante imbricada no imaginário social, qual seja, a de que, se há crime, deve haver castigo. No estágio atual do Estado de Direito, sabe-se que, de maneira geral, o castigo é materializado no cárcere, estando as instituições de justiça muito satisfeitas com a transferência dos suplícios para a privação de liberdade. Contudo, sabe-se que a "sofisticação" sancionadora do processo criminal, muito mais do que construir prisões, criou um complexo industrial-prisional, sendo bastante difícil, nos dias de hoje, separar as dimensões entre lucro, cárcere, pobreza, raça e classe.

Em segundo lugar, há que se falar na ausência de participação da vítima na tríade processual. Ora, como a pessoa diretamente atingida pelo conflito não possui um papel ativo nesse sistema? Conforme cediço, a vítima do crime limita-se a prestar declarações em juízo, respondendo aos questionamentos dos que são considerados os verdadeiros atores processuais.

Em terceiro lugar, é possível refletir sobre o caráter generalizante das tipificações penais. Afirma-se isso, pois, independentemente do pano de fundo do cometimento do crime, se a conduta praticada capitula-se ao descrito na legislação sancionadora, há que se falar na necessidade de persecução criminal.

Ainda que se fale em individualização da pena e do devido processo legal, não se pode olvidar que o Código Penal destina um tratamento homogêneo para situações que podem ser severamente distintas. Afinal, como a letra da lei poderia dar conta do contexto particularizante de cada crime? Não está aqui se falando em antecedentes criminais, reincidência, atenuantes ou agravantes, mas sim em histórias de vida e de relacionamentos.

Considerando esse estado de coisas, é simples perceber que há que se falar em uma 
espécie de ilegitimidade no sistema de justiça criminal vigente. Como explanado, as necessidades da vítima e do ofensor são transferidas para terceiros, a legislação penal não abarca a complexidade de cada delito e uma lógica binarizante entre crime e castigo é extremamente predominante.

Se há ilegitimidades no sistema, necessariamente, não deve haver espaço para conformismos. É nesse sentir que se torna interessante abrir um novo olhar para o sistema de justiça criminal. Um olhar que não normalize, concilie ou abra arestas, mas um olhar que rompa. Por esse motivo, pretendeu-se aqui estudar, em que medida - levando-se em conta as naturais limitações - e de que forma a justiça restaurativa pode romper com o sistema penal hoje oferecido.

Em um primeiro momento, portanto, abordou-se o que aqui foi considerado o coração da justiça criminal punitivista: a lógica do crime e castigo. Em seguimento, foi apresentada, em breve síntese, as bases teóricas do modelo restaurativo, visando a reconstrução de relacionamentos. Por fim, descreveu-se uma prática restaurativa utilizada na comarca de Novo Hamburgo, no Rio Grande do Sul, a fim de serem apontadas tensões entre teoria e prática.

\section{Abolindo a lógica do crime e castigo}

Estariam as prisões obsoletas? Esse é o questionamento que Angela Davis pretende discutir em obra autoral que leva esse título. Muito mais do que imaginar o desaparecimento de fortalezas de concreto repletas de indesejáveis, a autora convida o leitor a refletir sobre a abolição de uma lógica. Afinal, por que fomos ensinados que se há crime deve haver castigo?

Nota-se, aqui, que castigo não é sinônimo de responsabilização. Uma leitura descontextualizada poderia formular o pensamento de que o cometimento de um crime gera isenção de qualquer espécie de reparação por parte daquele que o praticou. Longe disso, a palavra castigo, ora empregada, representa uma alegoria. Castigo, nesse trabalho, guarda correspondência ao encarceramento, a uma pena, a imputação de culpa e a marginalização do indivíduo perante a comunidade que pertence.

É nesse sentido que Angela Davis discorre que, o rompimento do modelo de justiça criminal atual, urge pela desvinculação não só do crime e do castigo, mas, sobretudo, da raça e punição, da classe e punição e do gênero e punição como relações sociais que sustentam as prisões (DAVIS, 2018, p. 92). A mensagem passada pela autora, portanto, é a de que a característica fundamental do sistema penal vigente é a seletividade. É dizer que as prisões 
são ocupadas por indivíduos bastante semelhantes. Dito isso, uma nova - ou velha - questão vem à tona: a quem interessa selecionar determinadas pessoas no interior de prisões? Veja-se em breve síntese.

De acordo com Vera Malaguti, a história da criminologia está imbricada no próprio seio do capitalismo. Isso porque, se o processo histórico de acumulação de capital fomentou, de um lado, aqueles que usufruíam da mais-valia, de outro, criou uma camada de cidadãos empobrecidos. A serviço do capital, o disciplinamento da classe empobrecida exerceria um papel primordial para o sucesso do sistema, de modo que, "a prisão, subordinada à fábrica, se converte na principal pena do mundo ocidental" (BATISTA, 2011, p. 26). Criminóloga crítica por essência, a lição a ser extraída da obra de Vera Malaguti é de que a classe trabalhadora empobrecida, ao revés de ser criminosa, era, em verdade, criminalizada.

Para Alessando Baratta essa criminalização ocorreria de maneira dupla. De um lado, determinados bens seriam estrategicamente escolhidos para receberem a tutela do direito penal, e, de outro, determinados indivíduos seriam igualmente escolhidos para receberem o estigma de violadores da norma, sendo considerados delinquentes (BARATTA, 2002, p. 161). Para o autor, a igualdade do Direito Penal se constitui como mito, sendo um direito burguês e desigual por excelência. Melhor explicando, a reflexão de Baratta converge no sentido de que o Direito Penal tipificou como crime as condutas que lesam os interesses das classes dominantes, a exemplo dos crimes patrimoniais. Por conseguinte, se as classes subalternas não são detentoras de bens patrimoniais de grande importância para o capitalismo, são os indivíduos pertencentes a ela que serão considerados desviantes. Logo, uma posição precária no mercado de trabalho, ao lado do desemprego, "revelam ser, antes, conotações sobre a base das quais o status de criminoso é atribuído" (BARATTA, 2002, p. 161).

Como forma de ilustrar as teorizações advindas da criminologia crítica, é pertinente citar alguns dados coletados pelo Departamento Penitenciário Nacional (DEPEN), do período de julho a dezembro de 2019. Assim, segundo esse órgão, os crimes contra o patrimônio lideram disparadamente o ranking de incidências por tipo penal. De um universo de 989.263 crimes praticados no período citado, 504.108 deles referem-se a delitos dessa natureza, seguido de 200.583 incidências da Lei de Drogas. Infere-se, portanto, que mais da metade da totalidade de crimes registrados no país dão conta da diminuição patrimonial de classes não marginalizadas.

Noutro giro, o mesmo órgão registrou, no ano de 2017, que o grau de escolaridade da 
população brasileira não se reflete no interior do sistema carcerário. Isso porque, no ano citado, 51,3\% das pessoas presas não possuíam sequer o ensino fundamental completo, ao passo que apenas 0,5\% delas chegou a concluir o ensino superior. Em somatório a esses dados, não poderia deixar de ser mencionado que, de acordo com o Anuário de Segurança Pública do ano de 2020, o perfil carcerário brasileiro é o de homens jovens, negros e de baixa escolaridade.

Ainda que essa afirmativa não seja nenhuma espécie de novidade, o documento também chama a atenção do leitor no que concerne a questão racial. Isso pois, 58,4\% das pessoas encarceradas no ano de 2005 eram pretas, ao passo que, em 2019, essas pessoas representaram 66,7\% dos presidiários, o que mostra um crescimento de 377,7\% de negros e negras na população carcerária brasileira em 14 anos (FÓRUM BRASILEIRO DE SEGURANÇA PÚBLICA, 2020, p. 306). Logo, é de se concluir que, de fato, as pessoas que estão sendo enviadas para as prisões brasileiras são jovens, negros, de baixa escolaridade e que cometeram crimes contra o patrimônio alheio. Ainda que se reportasse à realidade estadunidense, é simples compreender a razão pela qual Angela Davis escreveu que um rompimento do modelo de justiça criminal deve quebrar não só a lógica do crime e castigo, mas também da raça, da classe e do gênero.

O retrato existente é simples de ser desenhado. A população substituível ao capital é descartada e controlada no interior de penitenciárias administradas pelo Estado. Segurança pública é pauta presente em discursos eleitorais, afinal, é preciso separar a população de bem daquela desviante. A suposta vítima do conflito transcende a pessoa lesada e passa a ser toda a sociedade. A administração do problema é retirada das partes envolvidas e transfere-se a sofisticadas engrenagens burocráticas do que se convencionou chamar de justiça criminal. Como se quebra, então, essa lógica?

É certo que essa pergunta extrapola em muito o que pode ser abordado nesse trabalho. A densidade teórica de um artigo científico não pode ter a pretensão de exaurir tão vasto campo. Afinal, o cerne do questionamento engloba sobretudo políticas públicas. Ângela Davis responde que para menos cadeias é preciso mais escolas, sistemas de saúde estruturados e oferta de empregos criativos. Entretanto, não pode ser olvidado que, pensar em alternativas ao modelo de justiça criminal vigente é o que se espera de estudiosos sobre o assunto. Alternativas estas que devem caminhar lado a lado das citadas políticas públicas. Vejamos o que a Justiça Restaurativa tem a oferecer, então. 
2 A Justiça Restaurativa - os conflitos sociais sob outra perspectiva

Antes de adentrarmos no que se propõe a Justiça Restaurativa, vale explorar um arcabouço teórico mais aprofundado, que dar-nos-á mais amparo para sustentar a maior possibilidade de eficácia de outros métodos resolutivos de conflitos penais, que não a lógica do crime-castigo.

Bourdieu, em sua obra "A dominação Masculina", apresenta-nos o habitus, que se trata de situações que se operam "sem necessidade de o agente raciocinar para se orientar e se situar de maneira racional num espaço" (BOURDIEU, 1989, p. 62), e isso se dá, porque o homem está em sociedade e todos os conceitos sociais estão nele. Logo, o habitus funciona como matrizes das percepções, dos pensamentos e das ações de todos os membros da sociedade.

Sendo assim, a lógica do crime-castigo e também a dominação masculina, como bem exemplifica Bourdieu, é algo que já vem impregnado na sociedade há anos e hoje expressa-se como "um conhecimento adquirido e também um haver, um capital de um agente em ação" (BOURDIEU, 1989,p. 61).

Contudo, o habitus precisa ser analisado de forma crítica, porque, para Bourdieu, este é um conceito que, apesar de útil, incomoda pela sua permanência, isto é, sua quase impossibilidade de mudança - o habitus adquirido até aqui é o que permanecerá, implicando em formações de conceitos fechados, em detrimento da transformação.

Logo, mais plausível para o que nos propomos a estudar nessa pesquisa, é atrelarmos o habitus ao conceito de conservação-dissolução desenvolvido por Bettelheim (1969), que preconiza uma análise do passado a fim de compreender a origem dos conceitos, que ainda ressoam na sociedade. Nesse tom,

Uma formação social jamais desaparece antes que estejam desenvolvidas todas as forças produtivas que ela pode conter, jamais relações de produção novas e superiores substituem as antigas antes que as condições materiais de existência destas relações desabrochem no próprio seio da velha sociedade (MARX, 1957, prefácio, p. 5).

À vista disso, o novo e o velho coexistem, ou seja, a lógica - o habitus - que aderimos ao longo de tempos - onde houver crime, que haja castigo. Assim, as lutas empreendidas para fazer cessar esse pensamento precisam ser desempenhadas no sentido de deslegitimar conceitos que engendraram nas engrenagens de toda a sociedade, fazendo-nos descredibilizar qualquer outra forma de resolução de conflito penal. 
É por esta razão que não se acredita em uma implementação radical, do dia para a noite, de uma Justiça Restaurativa, por exemplo, mas o que se propõe é um entendimento, a princípio, de toda essa lógica que nos foi imposta para aos poucos pensarmos em outros caminhos para os conflitos penais.

Vale salientar, que isso deve ser trabalhado não só com o sistema de justiça, mas perante toda a sociedade. Vejamos um exemplo, não se acredita em uma mudança radical decorrente de uma relação violenta, quando se trabalha exclusivamente com a vítima, porque, enquanto um lado está apta a mudanças, de outra banda permanece o que sempre foi, podendo tornar a convivência ainda mais violenta (SAFFIOTI, 2011, 68).

Portanto, diante desse panorama de ilegitimidade do sistema penal, a justiça restaurativa destaca-se como um arquétipo para uma nova forma de justiça, que passa a enfrentar os conflitos penais a partir da perspectiva do diálogo-consenso, desconsiderando a ideia imbricada no senso comum de culpa-castigo e recolocando vítima e ofensor como protagonistas.

O conceito de justiça restaurativa não é único, definido, tampouco pacífico entre os doutrinadores, posto que há uma grande diversidade de orientações e práticas nessa seara, é o que apontam Gery Jonhtone e Daniel Van Ness, citado por Achutti:

\begin{abstract}
Alguns consideram a justiça restaurativa como uma nova técnica social ou programa que pode ser usado no interior dos nossos sistemas de justiça criminal. Outros procuram, em última análise, abolir grande parte do edifício de punição do Estado e substituí-lo por respostas baseadas na comunidade que ensinam, curam, reparam e restauram as vítimas, autores de crimes e suas comunidades. Outros, ainda, aplicam a visão de crime e restauração a todos os tipos de conflitos e danos. Na verdade, o objetivo final e o foco principal, eles sugerem, deveria ser a mudança como vemos a nós mesmos e nos relacionamos com os outros na vida cotidiana (ACHUTTI, 2009, p. 85).
\end{abstract}

Porém, uma coisa é comum aos que pensam na justiça restaurativa como uma boa alternativa para a solução de conflitos. Fala-se isso em virtude de todos os conceitos de justiça restaurativa convergirem para um ponto de partida, qual seja, uma inversão de objeto (MAGALHÃES, 2014, p. 33). Hoje vislumbra-se o crime à luz das suas consequências, bem como das relações sociais afetadas pela conduta, deixando de lado os focos tradicionais da intervenção penal, que são o crime propriamente dito, o delinquente (ofensor) e a reação social.

Ante esse contexto, é preciso entender o crime em si, para depois analisá-lo sob o panorama da justiça restaurativa. Dessa maneira, o crime é tido como uma violação de relacionamentos, cuja vítima é diretamente ofendida, mas que o ofensor, antes de ofender, 
pode ter sido ofendido. É dizer que, esse ponto de vista acredita que os indivíduos considerados desviantes foram vítimas de violações pretéritas. Como exemplos desse panorama, aponta-se situações de abuso na infância, racismo e exclusão social ocasionada pela privação de direitos básicos, como saúde, lazer, educação e moradia.

Analisando esse ciclo de violência pelas lentes da justiça restaurativa, percebe-se que, para esse modelo de resolução de conflitos, responder à violência marginalizando os indivíduos por meio da imposição de penas, mais colabora com todo esse ciclo do que o previne ou exclui. Nessse tom, ponderar os valores da justiça retributiva e restaurativa é ressignificar escolhas, que, possivelmente, colaborarão para um resultado diferente do apresentado hoje.

Vendo o crime sob a ótica retributivista, observa-se o modelo de justiça penal tradicional, que o crime é definido pela violação à lei; os danos são definidos em abstrato; o Estado e o ofensor são as partes do processo; as necessidades e direitos das vítimas são ignorados e as dimensões interpessoais são irrelevantes (ZEHR, 2008).

De outra banda, a justiça restaurativa apresenta a percepção reconstrutiva do crime, que o define como uma violação de relacionamento, em que os danos são definidos concretamente; as vítimas e o ofensor são as partes no processo e as necessidades, os direitos da vítima, bem como as dimensões interpessoais são preocupações centrais.

Todavia, é preciso pontuar que o sentido pacificador da justiça restaurativa, ainda que bastante atraente para aqueles que acreditam na obsolescência das prisões, encontra uma resistência ferrenha. No senso comum, existe uma associação muito forte entre segurança pública e incremento do poder punitivo. É por esse motivo que, não raro, escuta-se chavões do tipo "lugar de bandido é na cadeia" ou "bandido bom é bandido morto". Fortemente influenciados por um sistema, por legislações e, consequentemente, por clamores midiáticos nesse sentido, acredita-se que a retribuição - culpa-castigo - propicia uma experiência de que a justiça está sendo feita.

Sendo assim, o saber jurídico penal debruça-se em organizar, discursivamente, as suas decisões e leis conforme convém a quem o sistema favorece. Ocorre que, o discurso ganha força quando esse pensamento extremo conquista espaço nos meios de comunicação e quando a opinião pública é judicializada. Essa simbiose entre mídia e sistema judiciário repercute nas decisões dos tribunais, uma vez que estes trabalham no sentido de atuarem como receptores e geradores de expectativas, mas que, muitas vezes, extrapolam ao que merecia o caso concreto 
(SICA, 2004).

Ante esse panorama, é possível fazer um paralelismo com a visão crítica de Noam Chomsky, afinal, "O tom marcial traz benefícios maiores para os que defendem a violência e a repressão estatais a fim de assegurar privilégios" (CHOMSKY, 2003, p. 159), que aponta o quanto a manutenção de uma imagem bélica dos tribunais prejudica a existência de qualquer forma de justiça informal e não repressiva (SICA, 2004).

Portanto, a insistência pelo enrijecimento do sistema penal, como ocorre com as legislações vigentes no país, que corroboram com os princípios e valores do sistema penal retributivo, faz crer que o provérbio francês, "Quanto mais as coisas mudam, mais ficam iguais", está cada vez mais atual, porque as mudanças alimentam o sistema penal tradicional e enfraquecem a possibilidade de uma justiça reconstrutiva, que proporcionaria um melhor aproveitamento para às partes.

É necessário mencionar também que a percepção tradicional do sistema de justiça criminal reverbera em algumas iniciativas que realizam uma espécie de conciliação com o sistema vigente, a exemplo da monitoração eletrônica, da prisão domiciliar e de projetos de "humanização das cadeias". Contudo, deve-se lembrar que um verdadeiro rompimento da lógica crime-castigo não comporta medidas penalizadoras, ainda que menos gravosas que o encarceramento. Tampouco os princípios da justiça restaurativa alinham-se a esses mecanismos. Afinal, esse cenário retrata uma extensão do sistema penal da cela para a sala dos ofensores da lei. Nesse tom, conforme o ensinamento do professor Kay Harris (KAY, 1987, pp. 12-21) especialista em sentenciamento, implementar uma justiça restaurativa tratase de adotar valores diferentes, e não adotar tecnologias de punição diferentes.

Romper com um modelo de justiça tradicional é aderir a um novo paradigma, que é mais do que uma forma de ver ou uma perspectiva. Como afirma Howard Zerh, encerrar essa lógica penal "exige uma teoria muito bem articulada, combinada a uma sólida gramática e uma física de aplicação - além de um certo grau de consenso" (ZEHR, 2008, p. 8), a fim de indicar uma direção que quebre com toda a tradição jurídica que envolve o binômio crimecastigo.

Não se quer dizer com isso que a justiça restaurativa é a solução para todos os problemas do sistema de justiça criminal existente, mas, não se pode negar, que ela aponta perspectivas relevantes para um novo paradigma na seara penal. Tanto é que o Conselho Nacional de Justiça (CNJ), publicou em 31 de maio de 2016, a Resolução n. 225/2016, que 
dispõe sobre a Política Nacional de Justiça Restaurativa no âmbito do Poder Judiciário e dá outras providências.

Desta feita, dada a relevância do tema e o seu acolhimento por algumas instituições, como o CNJ, é importante que se entenda como a justiça restaurativa está sendo tratada pelo judiciário brasileiro na prática jurídica, a fim de que se possa analisar a forma que esse modelo de resolução de conflitos está sendo executado. Isso porque, espera-se que a justiça restaurativa seja acolhida como uma alternativa vanguardista e não como mais um incremento do poder punitivo estatal. É o que se segue.

3 Do papel à prática - uma tentativa de implementação da Justiça Restaurativa

Retomando a percepção de crime, que se trata de uma violação de relacionamentos, será interessante analisar a aplicabilidade da justiça restaurativa nos crimes contemplados pela Lei Maria da Penha, já que esta lida, justamente, com conflitos que estão diretamente ligados à relacionamentos, isto é, da mulher com o seu companheiro, com o filho e, de um modo geral, com a comunidade.

Então, partindo de um pressuposto utilizado pela justiça restaurativa, qual seja, o de reconstruir as relações que foram atingidas por ações que são tipificadas como crimes, evitando o cárcere, é importante trazer à baila as novas práticas utilizadas em Novo Hamburgo, no Rio Grande do Sul, para lidar com os casos de violência doméstica e familiar contra a mulher.

Clara Welma Florentino e Silva, em sua dissertação apresentada ao Programa de Pósgraduação em Direito da Universidade de Brasília, intitulada "Justiça restaurativa em conflitos envolvendo violência doméstica no Brasil: análise a partir da experiência de Novo Hamburgo - RS", debruçou-se sobre as hipóteses de como tem sido introduzida a justiça restaurativa no cenário brasileiro, principalmente na seara da violência doméstica. Portanto, a escolha do exemplo trazido para o presente trabalho, encontra inspiração no locus de pesquisa da autora, bem como nas suas vivências quando da realização da pesquisa etnográfica realizada na comarca de Novo Hamburgo (SILVA, 2019).

Para iniciar a explanação acerca do passo a passo dessas novas práticas, cumpre esclarecer que as alternativas restaurativas não estão desvinculadas do processo penal, isto é, o juizado de violência doméstica de Novo Hamburgo utiliza a justiça restaurativa almejando transformações extraprocessuais, mas isso não traz interferências relevantes no curso do processo (SILVA, 2019). 
Sendo assim, o que ocorre em Novo Hamburgo é que, nas audiências de acolhimento, o (a) magistrado (a) separa alguns processos, a seu julgo, para serem encaminhados à justiça restaurativa, isto é, as partes são convidadas a participarem dos círculos de construção de paz.

Os círculos de construção da paz é um método, cujo principal referencial teórico é Kay Pranis, que propõe processos de contação de histórias, cujo objetivo é movimentar uma escuta diferente diante de outras histórias. Eles, então, impulsionam os participantes a tentarem entender as situações dos outros e buscar boas saídas longe da repressão. Kay Pranis destaca que a partilha das histórias de luta, dor, alegria, desespero e superação são um refrigério para os participantes do círculo (PRANIS, 2010, p. 56).

Em Novo Hamburgo esses círculos acontecem em uma das salas do Centro Judiciário de Solução de Conflitos e Cidadania - CEJUSC. A disposição dos objetos na sala é pensado, inclusive, para proporcionar um ambiente de conciliação. Sendo assim, de um lado, há um painel, onde são reproduzidos vídeos, e, no outro, tem uma mesa, em que as facilitadoras colocam os materiais que serão utilizados nas atividades, além de biscoitos, água, chá, café (SILVA, 2019, p. 81). Essa experiência dos círculos de construção da paz, vivenciado em Novo Hamburgo, tem bastante afinidade com o que propõe Kay Pranis

\footnotetext{
Os participantes se sentam nas cadeiras dispostas em roda, sem mesa no centro. Às vezes se coloca no centro algum objeto que tenha significado especial para o grupo, como inspiração, algo que evoque nos participantes valores e bases comuns. O formato espacial do círculo simboliza liderança partilhada, igualdade, conexão e inclusão. Também promove foco, responsabilidade e participação de todos (PRANIS, 2010, p. 25).
}

Além de um ambiente adequado, o juizado preza pela periodicidade dos círculos, de forma que, assim que um grupo termine outro comece, bem como pelo engajamento da comunidade, com o fulcro de evitar novos crimes e transformar a sociedade, que sempre é citada pelos participantes e pelas facilitadoras (SILVA, 2019, p. 83).

Para contextualizar o supramencionado, reproduzir-se-á um caso apontado e acompanhado por Clara Welma. Ana e Miguel, casal que participou dos círculos restaurativos, retratados no processo $n^{\circ} 05$, tiveram o processo mais longo, porque participaram de cinco encontros, que sucederam da seguinte forma.

A proposta do primeiro círculo era identificar os valores centrais dos participantes, a fim de criar um ambiente confortável que aumente a confiabilidade entre as pessoas e elas sentiam-se confortáveis para expressar sentimentos e estabelecer vínculos. O segundo círculo estava voltado para o fortalecimento da autoestima de cada participante, a partir das 
particularidades positivas da vida de cada um. Já o terceiro círculo pretendia estimular o cuidado pessoal dos participantes, partindo da premissa de que cada participante deve prezar por um relacionamento saudável consigo, buscava-se desenvolver relações saudáveis com outrem. O quarto círculo tinha o intuito de trabalhar a interioridade de cada participante, o "eu" de cada um, bem como fazer acordos para melhorar a sua convivência em comunidade. $\mathrm{O}$ quinto e último círculo, frisava o já trabalhado nos anteriores, ou seja, a conscientização dos pontos fortes de cada um e fortalecer os aspectos positivos da vida familiar (SILVA, 2019, p. 86).

Esses são os objetivos trazidos pelos círculos dos processos restaurativos, que visam, por suposto, abordar as finalidades da justiça restaurativa. Mas, quais seriam essas finalidades? Alguns debates são travados acerca desse assunto, principalmente, no que tange a violência doméstica e familiar contra a mulher, que são conflitos complexos, que envolvem muita particularidade.

Uma das problemáticas que algumas vítimas e defensores das vítimas enfrentam, diante desse modelo proposto de justiça restaurativa, é por pensar que ela estimula ou impõe que as vítimas perdoem ou reconciliem-se com os seus ofensores. No entanto, Zehr, esclarece que esse não é o objetivo do programa, mas que a justiça restaurativa propicia muito mais que haja a reconciliação (ZEHR, 2008), isto é, a restauração das relações, que em um ambiente litigioso, como ocorre no modelo de justiça penal tradicional.

Todo esse embate que envolve a justiça restaurativa faz parte da tentativa de pensar uma nova justiça pautada em valores reconstrutivos. Então, os que veem problemas no modelo restaurativo aplicado aos casos de violência doméstica em Novo Hamburgo têm o intento de aprimorá-lo, a fim de que se torne cada vez melhor para as partes. Mas, vale reconhecer que a iniciativa de Novo Hamburgo já demonstra uma preocupação em romper com o modelo punitivo existente.

Ante tal conjuntura, o importante é entender que, diante das circunstâncias concretas apresentadas nos casos de violência doméstica contra as mulheres e tendo em vista toda a conjuntura social que as envolve, a justiça restaurativa precisa debruçar-se sobre a estrutura social em que essas agressões desenvolvem-se para, a partir dessas construções sociais, vislumbrar soluções pacificadoras.

Todavia, conforme já introduzido no início desse tópico, o modelo de justiça restaurativa de Novo Hamburgo, por exemplo, não obsta as medidas penalizadoras da Lei 
Maria da Penha ou de qualquer outra legislação penal, podendo, inclusive, incidir um bis in idem, porque além de participar do tratamento de reconciliação proposto pela justiça restaurativa, o ofensor ainda responde penalmente pelo crime que cometeu. Isso se deve pelo fato de que, o processo penal brasileiro não disciplina sobre os círculos restaurativos ou práticas semelhantes, como uma alternativa resolutiva da infração legal.

Sendo assim, o que se pode notar é que todo esse protótipo de outros caminhos para pensar a resolução de conflitos penais está mais para práticas restaurativas do que propriamente para Justiça Restaurativa. Posto que, esta vislumbra romper com a lógica do crime-castigo de forma profunda, isto é, reconstruindo conceitos e ideias - integridade, humanização, sensibilidade, ressocialização, diálogo, reintegração - enquanto que as práticas restaurativas funcionam como paliativos apenas, porque reconhecem a ineficiência punitivista do sistema para lidar com os conflitos, mas não abrem mão de ter o sistema penal como o protagonista dessa resolução.

Em um artigo desenvolvido por Marília Montenegro, Carolina Salazar e Fernanda Rosemblatt, intitulado "Para além do 'mundo jurídico': um diálogo com as pesquisas multidisciplinares (ou Varas) de Violência Doméstica", fruto de uma pesquisa de campo diagnosticou entre uma das equipes multidisciplinares junto a determinada Vara ou Juizado de violência doméstica, que os próprios integrantes dessas equipes mostram-se preocupados com duas circunstâncias, quais sejam: a falta de capacitação das pessoas para trabalharem com a Justiça restaurativa, bem como o receio de que essas práticas sejam impostas "de cima para baixo" (MONTENEGRO, ROSEMBLATT, SALAZAR, 2021, p. 634).

Estas preocupações estão correlacionadas, porque, de fato, sendo a Justiça Restaurativa uma imposição do Conselho Nacional de Justiça (CNJ) e aplicável por atores descapacitados, incorre-se no mesmo erro ou piores. Não se trata de uma justiça consensual, contudo de uma proposta de repensar a justiça, mas isso não ocorre ou pelo menos não deve ocorrer abruptamente, ainda é preciso entender o habitus que envolve toda a conjuntura e promover o que Bettelheim (1969) chama de conservação-dissolução.

Sendo assim, a descrença no que diz respeito a implementação de uma justiça restaurativa decorre, justamente, da falta de distinção de conceitos entre um modelo de justiça consensual, implementado no Brasil pela Lei 9.099/95 - Lei dos Juizados Especiais Criminais -e a justiça restaurativa. No Brasil, o fato é que a justiça consensual resume-se a esvaziar as prateleiras superlotadas das Varas e, por conseguinte, aliviar a máquina estatal (SICA, 2004). 
Só que a Justiça Restaurativa, ante todas as ponderações feitas nesse trabalho, não tem esse intuito, porque ela tem como objetivo precípuo manter a solução negociada no conflito afastada do processo penal. O que não ocorre no exemplo trazido, mostrando, portanto, um desvirtuamento de finalidade.

Assim, no atual estágio de desenvolvimento do processo penal brasileiro, o Estado continua sendo considerado a vítima do conflito e o protagonista da persecução penal, responsável por decidir o destino de relações interpessoais das quais não tem familiaridade.

Logo, é de se perceber que a justiça restaurativa encontra-se à margem do processo penal brasileiro, o que só reforça a centralidade do sistema penal vigente. Por esse motivo, mesmo que a justiça restaurativa apresente-se como uma nova forma de administração de conflitos, é preciso cautela para que essa alternativa não acabe se constituindo como uma nova forma de controle social ou, ainda, reforce o poder de punir.

\section{CONCLUSÃO}

A partir das considerações acima expostas, demonstrou-se que o sistema de justiça criminal vigente é pautado por princípios retributivistas, que respondem a uma lógica binária entre o crime e o castigo. Dessa forma, discorreu-se sobre os castigos materializados no cárcere, a partir das lentes de criminólogos críticos que explicam a intimidade entre as prisões e o capitalismo e, consequentemente, a intimidade entre as prisões e indivíduos dispensáveis ao capital.

Após esse momento, apresentou-se a justiça restaurativa como um modelo que se emancipa do binarismo entre crime e punição, estando mais interessado em reconstruir relacionamentos pela perspectiva do diálogo-consenso, recolocando a vítima do conflito social no centro, junto do ofensor, da comunidade e de outros possíveis envolvidos no problema. Assim, foi visto que a justiça restaurativa, em essência, desacopla-se do Estado-juiz e pretende pacificar relações sem a interferência de terceiros investidos de jurisdição.

Em sequência, descreveu-se, de maneira breve, uma espécie de protótipo de justiça restaurativa realizado na cidade de Nova Hamburgo, no Rio Grande do Sul. No caso tratado, os círculos restaurativos que foram citados visavam a administração de um conflito envolvendo violência doméstica, o qual tradicionalmente é chancelado pela Lei Maria da Penha. A escolha por esse caso foi justificada em razão das agressões tratadas serem advindas de uma relação familiar, a qual se amolda bastante a razão de ser da justiça restaurativa, que, 
repise-se, visa reconstruir dados relacionamentos em dada comunidade.

Destrinchando-se o caso escolhido, foi percebido que os círculos restaurativos ocorreram de maneira paralela ao processo criminal tradicional. Nesse sentido, a prática visava uma espécie de reconciliação extrajudicial e não a administração do conflito propriamente dito. Isso porque, independentemente do resultado dos círculos restaurativos, ao ofensor seria destinado o tratamento tradicional do processo penal brasileiro.

Nessa perspectiva, chega-se a conclusão de que, longe de romper com a lógica do crime e castigo - ainda que tenha potencial para tanto - o caso da justiça restaurativa de Novo Hamburgo apenas reforça a centralidade do Estado-juiz e do crime e da punição. Afinal, não importa a quantidade de círculos restaurativos a que se submeta, ou a que relações reconstrua, o ofensor ainda ostentará a qualidade de réu em um processo criminal, sendo passível de ser enviado ao cárcere.

Percebeu-se, por tudo isso, que, se a justiça restaurativa for conduzida apenas dessa forma marginalizada ao processo penal, essa nova perspectiva de resolução de conflitos não será capaz de romper com as estruturas que convergem no sentido da ilegitimidade do sistema de justiça criminal vigente. Não se pode confundir, portanto, círculos restaurativos com sessões de terapia. Deve-se ter em mente que a justiça restaurativa é capaz de romper uma lógica, sob pena de ser considerada apenas como um acessório simpático que promove bemestar.

\section{REFERÊNCIAS}

ACHUTTI, Daniel. Modelos Contemporâneos de Justiça Criminal: justiça teratêutica, instantânea e restaurativa. Porto Alegre. Livraria do Advogado Editora, 2009.

BARATTA, Alessandro. Criminologia crítica e crítica do Direito Penal: introdução à sociologia do direito penal. Tradução: Juarez Cirino dos Santos. 3. ed. Rio de Janeiro: Revan, 2002.

BATISTA, Vera Malaguti. Introdução crítica à criminologia brasileira. Rio de Janeiro: Revan, 2011.

BETTELHEIM, Charles. Remarques Théoriques par Charles Bettelheim. In: EMMANUEL, 
A. L'échange inégal; présentation et remarques théoriques de Charles Bettelheim. Paris: Librairie François Maspéro, 1969.

BOURDIEU, Pierre. A dominação masculina. Rio de Janeiro: Bertrand Brasil, 1999.

BRASIL. Lei n. ${ }^{\circ} 11.340$, de 7 de agosto de 2006. Institui a Lei Maria da Penha. Lei $\mathrm{n}^{\mathrm{o}}$ 9.099, de 26 de setembro de 1995. Institui a Lei dos Juizados Especiais Cíveis e Criminais.

CHOMSKY, Noam. Contendo a democracia. Trad. Vera Ribeiro. Rio de Janeiro: Record.

DAVIS, Ângela. Estarão as prisões obsoletas? 1. ed. Rio de Janeiro: Difel, 2018.

DEPARTAMENTO PENITENCIÁRIO NACIONAL. Levantamento nacional de informações penitenciárias. Disponível em: http://antigo.depen.gov.br/DEPEN/depen/sisdepen/infopen. Acesso em: 01 nov. 2020.

DEPARTAMENTO PENITENCIÁRIO NACIONAL. Levantamento nacional de informações penitenciárias. Disponível em:

http://antigo.depen.gov.br/DEPEN/depen/sisdepen/infopen/relatorios-sinteticos/infopen-jun2017-rev-12072019-0721.pdf. Acesso em 30 out. 2020.

FÓRUM BRASILEIRO DE SEGURANÇA PÚBLICA. Anuário nacional da segurança pública 2020. Disponível em: https://forumseguranca.org.br/wpcontent/uploads/2020/10/anuario-14-2020-v1-interativo.pdf. Acesso em: 30 out. 2020.

HARRIS, Kay. "Strategies, Values and Emerging Generations of Alternatives to Incarceration", New York University Review of Law and Social Change, XII, nº 1, 1983-84. Observations of a 'Friend of the Court' on the Future of Probation and Parole, Federal Probation, LI, n⿳⺈ 4, 1987.

MAGALHÃES, Júlia Schilling. Aproximações entre justiça restaurativa e abolicionismo penal. f.79. Trabalho de conclusão de curso - Departamento de Ciências Jurídicas da 
Universidade Federal do Rio Grande do Sul, 2014.

MONTENEGRO, Marília Pessoa de Melo; ROSEMBLATT, Fernanda Cruz da Fonseca;

MEDEIROS, Carolina Salazar I'Armée Queiroga de Medeiros. Para além do “mundo jurídico": um diálogo com as equipes multidisciplinares de Juizados (ou Varas) de Violência Doméstica. Revista Direito e Práxis, Rio de Janeiro, Vol. 12, nº 01, 2021.

PRANIS, Kay. Processos Circulares de Construção de Paz. Trad. Tônia Van Acker. São Paulo: Palas Athena, 2010.

SAFIOTTI, H. I. B. Gênero, Patriarcado e Violência. São Paulo: Editora Fundação Perseu Abramo, 2011.

SICA, Leonardo. Justiças restaurativa: críticas e contracríticas. Porto Alegre, 2004.

Disponível em: <https://stqadvogados.com.br/download/Justica-restaurativa_criticas-econtracriticas.pdf>; Acesso em 05/11/2020.

SILVA, Clara Welma Florentino e. Justiça restaurativa em conflitos envolvendo violência doméstica no brasil: análise a partir da experiência de Novo Hamburgo - RS. 138f.

Dissertação (Mestrado em Direito) - Programa de Pós Graduação em Direito da Universidade de Brasília, 2019.

ZEHR, Howard. Trocando as lentes - um novo foco sobre o crime a justiça restaurativa. São Paulo: Palas Athena, 2008. 